\title{
The Development and Validation of a Dissolution Method for Clomipramine Solid Dosage Forms
}

\author{
Mehdi Ansari 1,3, Maryam Kazemipour ${ }^{2}$, Javad Talebnia ${ }^{1}$
}

email:mansari1345@yahoo.com

\begin{abstract}
Dissolution testing has emerged in the pharmaceutical field as a very important tool to characterize drug product performance. Clomipramine $\mathrm{HCl}$ as a frequently used antidepressant has no dissolution method in its monograph in BP or USP. In vitro dissolution tests of solid oral dosage forms of clomipramine were performed by various methods using different test conditions but always under "sink" conditions. Release profiles of different dosage forms of clomipramine show that release rate from capsules is much faster than from film coated tablet and that release from film coated tablet is faster than from the sugar-coated tablet. Dissolution of almost all forms was complete at 45 minutes. The in vitro release profiles of various tests were compared for their similarity using the $\mathrm{f} 2$ test. Results of this test indicate that in most cases dissolution profiles of the different products were significantly different from each other. Under certain conditions, tablets had a more discriminating profile than capsules under the same test conditions. A method using $\mathrm{HCl}$ as the dissolution medium in USP Apparatus 2 and stirring speed of $75 \mathrm{rpm}$, for all solid oral dosage forms of clomipramine could reliably discriminate among different products, if they are truly different. With these conditions, more than $80 \%$ of the label amount is released over 30 minutes.
\end{abstract}

\section{Introduction}

D rug absorption from solid dosage forms after oral administration depends on the release of the drug substance from the drug product, the dissolution or solubilization of the drug under physiological conditions, and the permeability across the gastrointestinal tract. Because of the critical nature of the first two of these steps, in vitro dissolution may be relevant to the prediction of in vivo performance. Based on this general consideration, in vitro dissolution tests for immediate release solid oral dosage forms are used: (a) to assess the lot-to-lot quality of a drug product; (b) to assess the stability of the drug product; (c) to ensure continuing product quality and performance after certain changes, such as changes in the formulation, the manufacturing process, the site of manufacture, and the scale-up of the manufacturing process; and (d) to develop new formulations. In formulation development, dissolution testing can aid in the selection of excipients, help optimize the manufacturing process, and enable formulation of the test product to match the release of the reference product [1 and 2].

Dissolution testing has emerged in the pharmaceutical field as a very important tool to characterize drug product performance. The dissolution test is an analytical technique that has undergone significant equipment modifications and improvements spanning the last decade. Dissolution has become an important and widely utilized test receiving more emphasis worldwide from regulatory authorities during the last 15 years. The significance of a dissolution test is based on the fact that for a drug to be absorbed and avail- able to the systemic circulation, it must previously be dissolved [3]. Therefore, dissolution tests are used not only for quality control of finished products, but also to assess several stages of formulation development, for screening and proper assessment of different formulations [4]. Basically, the dissolution test makes it possible to assess the dissolution properties of the drug itself and thereby to select the most appropriate excipients and to optimize proportions among them to obtaining the desired drug release behavior. Moreover, when an 'in vitro/in vivo' correlation is available, dissolution can be used as a test to reflect the bioavailability of a product in humans and therefore to determine the actual bioequivalence of different products containing the same drug at the same dosage.

During a preformulation study, preliminary testing conditions are commonly elaborated taking into consideration the state of the art for dissolution testing. Different official apparatus are available and, for each, Compendia, e.g., USP, $\mathrm{BP}$, and $\mathrm{EP}$, report detailed specifications in both general chapters [5 and 6] and individual monographs on solid oral dosage forms. Dissolution tests of conventional dosage forms have been successfully implemented, and formal guidelines exist which provide useful recommendations for their evaluation [7].

In any case, it is important to point out that none of the purposes for which dissolution tests are used can be fulfilled by an in vitro test without sufficient reliability, where this is defined as a system being experimentally sound, yielding precise, accurate and repeatable results [8]. A recent international collaborative study indicated that drug

\footnotetext{
'Department of Pharmaceutics, Faculty of Pharmacy, Kerman Medical Sciences University, Kerman, Iran

${ }^{2}$ Department of Chemistry, Faculty of Sciences, Kerman Azad University, Kerman, Iran
}

${ }^{3}$ Corresponding author, Department of Pharmaceutics, Faculty of Pharmacy, Kerman Medical Sciences University, Kerman, Iran 
dissolution testing is a highly variable technique [9]. As a consequence, in many cases the impact of formulation or manufacturing changes on drug release properties may not be detected, or, on the contrary, not true differences, but rather differences caused by test variability, could be recorded. Thus, careful control of experimental conditions is necessary in order to suitably reduce test-to-test variability and improve test reproducibility and reliability.

The validation of the dissolution test can be divided into two parts. The first regards equipment validation; equipment has to be calibrated taking into consideration the specifications for geometry and alignment of the dissolution apparatus [10]. The second concerns test validation; it requires the study of the performance parameter precision [5]. The evaluation of precision is very important in order to assess the reliability of the data obtained by the dissolution test. In fact, it is true that a more discriminating dissolution method is preferred, but it is also true that a reliable dissolution test is of utmost importance. A dissolution test with a good precision, for example, makes it possible to efficiently compare different alternative formulation candidates to select the dosage form with the most suitable and reproducible drug release profile. At the time of the dissolution test development, however, in vivo human data is normally not available. Instead, prior to the human clinical
Table 1. Dissolution conditions that were used in this study

\begin{tabular}{|ll|}
\hline & Condition \\
\hline Method & USPI (Basket) - USP II (Paddle) \\
\hline Medium & $\mathrm{HCl} 0.1 \mathrm{~N}$ - Phosphate Buffer at 7.0 pH \\
\hline Speed & $50 \mathrm{rpm}-75 \mathrm{rpm}$ \\
\hline
\end{tabular}

studies, dissolution data must usually be generated without the benefit of comparative rankings between formulations or lots, estimated in vivo absorption rates, or any other information that could be used to guide the development of a discriminating dissolution test [11 and12].

Clomipramine is a chlorinated analogue of imipramine with both antidepressant and anti-obsessional properties [13]. Clomipramine is an organic base of highly lipophilic nature. Its $\mathrm{HCl}$ salt is freely soluble in water. There is no official method for determination of dissolution rate of clomipramine hydrochloride solid oral dosage forms. A review of the literature indicated that there was no reported dissolution method for clomipramine products.

See Development and Validation ... continued on page 20 


\section{Development and Validation ... continued}

Consequently, the in-house development of a precise, validated, and reliable dissolution method for clomipramine solid oral dosage forms was necessary in order to support the product development and quality control efforts. This paper describes the development and validation of the dissolution methodology for clomipramine solid products.

\section{Experimental}

\subsection{Materials}

Clomipramine $\mathrm{HCl}$ pharmaceutical grade was kindly donated by Shahr Daru Pharmaceutical Co. (Iran); Hydrochloric acid (Merck, Darmstadt, Germany), was used as received. Clomipramine $\mathrm{HCl}$ film coated tablets were obtained from Shahr Daru Pharmaceutical Co. (Iran); labeled to contain $10 \mathrm{mg}, 25 \mathrm{mg}$, and $50 \mathrm{mg}$ Clomipramine $\mathrm{HCl}$. Anafranil ${ }^{\top}$ capsules contained $10 \mathrm{mg} 25 \mathrm{mg}$, and 50 $\mathrm{mg}$ clomipramine $\mathrm{HCl}$ manufactured by Novartis (Switzerland). Anafranil ${ }^{\oplus}$ sugar coated tablets labeled to contain $10 \mathrm{mg}$ clomipramine $\mathrm{HCl}$ were obtained from Ciba Geigy (England). Doubly distilled water was used throughout the study.

\subsection{Preparation of standard solutions}

Clomipramine stock standard solution was prepared at a concentration of $100 \mathrm{mg} / \mathrm{mL}$ in water. The clomipramine stock standard solution was diluted to obtain the known standard concentrations of 5, 10, 15, 20, 25, 30, 40, and 50 $\mathrm{mg} / \mathrm{mL}$ in either $1 \mathrm{~N} \mathrm{HCl}$ or $\mathrm{pH} 7.0$ phosphate buffer. The buffer was prepared by mixing $50 \mathrm{~mL}$ of $0.2 \mathrm{M}$ potassium dihydrogen orthophosphate with $29.63 \mathrm{~mL}$ of $0.2 \mathrm{M}$ sodium hydroxide volumetric solution and diluting to $200 \mathrm{~mL}$ with water. UV absorbance of each standard solution was measured spectrophotometrically (UV/Vis spectrophotometer Shimadzu 2100, Tokyo, Japan) at $252 \mathrm{~nm}$ with the mean data $(n=6)$ used for the calibration curve. The concentration of dissolved drug in sample solutions was spectrophotometrically monitored.

\subsection{Dissolution test conditions and analysis procedure}

Dissolution studies on three commercially available products (film coated tablets, sugar coated tablets and capsules) of clomipramine $\mathrm{HCl}$ were conducted using USP Apparatus 1 and 2 (basket and paddle method, respectively, Erweka DT80, Germany). The dissolution medium was $900 \mathrm{~mL}$ of either $\mathrm{pH} 1$ hydrochloric acid aqueous solution, or $\mathrm{pH} 7.0$ phosphate buffer at $37 \pm 0.5^{\circ} \mathrm{C}$ and stirred at 50 and $75 \mathrm{rpm}$. The dissolution test was performed on each product using conditions summarized in Table 1.

In all experiments, $5 \mathrm{ml}$ sample aliquots were withdrawn at $5,10,15,20,25,30,45$, and 60 minutes and replaced with an equal volume of the fresh medium to maintain a constant total volume. Samples were assayed by the previously
Figure 1. Dissolution profiles of Anafranil ${ }^{\circledR}$ Capsules in different dissolution conditions. $W=p H 7.0$ Buffer; $H=H C l ; P=$ Paddle; $B=$ Basket; $50=50$ rpm; $75=75 \mathrm{rpm}$

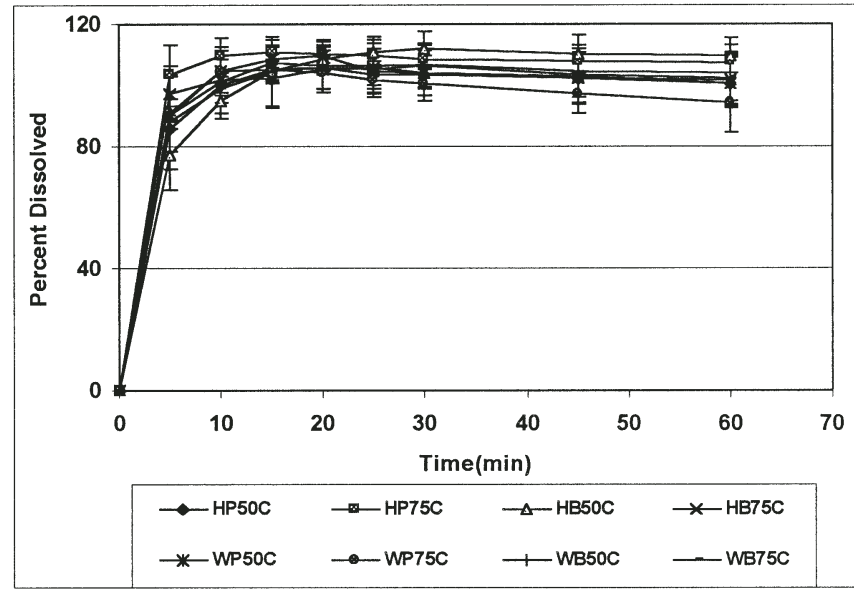

Figure 2. Dissolution profiles of Anafranil ${ }^{\circledR}$ Sugar Coated (SC) tablets in different dissolution conditions

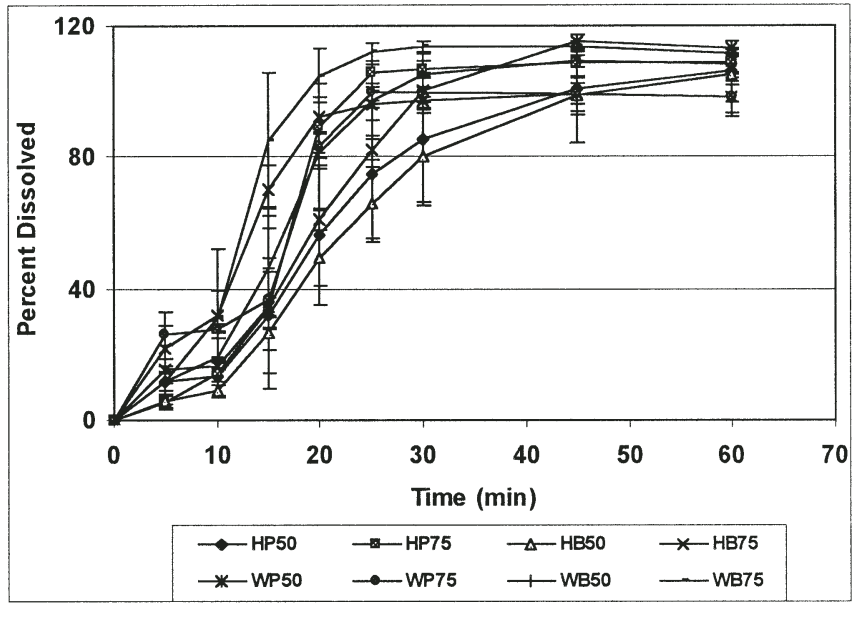

Figure 3. Dissolution profiles of clomipramine HCl Film Coated (FC) tablets in different dissolution conditions

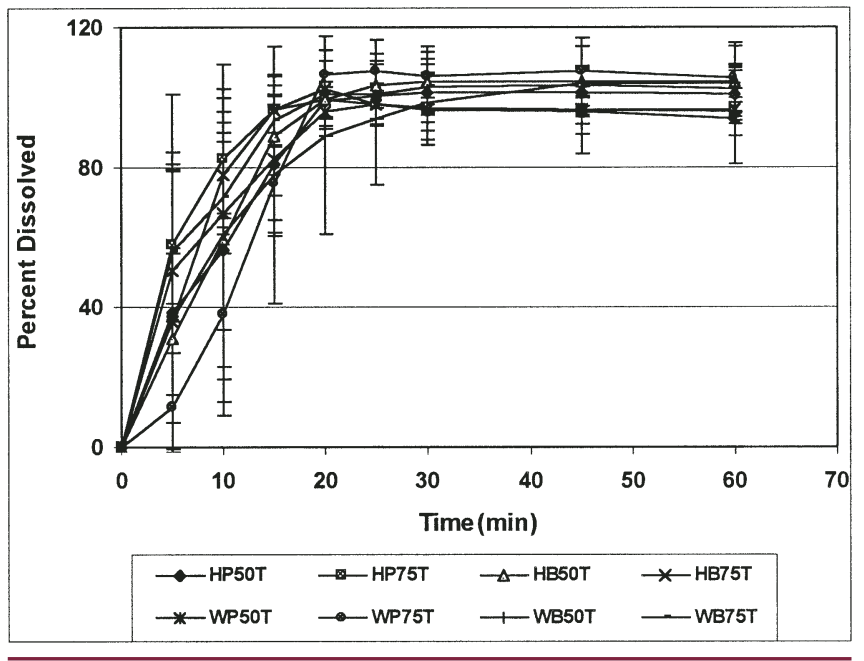


Table 2. The similarity factor, $\mathrm{f} 2$, between different dissolution conditions for capsule

\begin{tabular}{|lcccccccc|}
\hline Dissolution Condition* & HP50 & HP75 & HB50 & HB75 & WP50 & WP75 & WB50 & WB75 \\
\hline HP50 & - & 46.7 & 61.9 & 58.9 & 69.8 & 70.3 & 76.2 & 87.6 \\
\hline HP75 & 46.7 & - & 38.1 & 60.9 & 55.0 & 55.0 & 52.3 & 48.2 \\
\hline HB50 & 61.9 & 38.1 & - & 46.0 & 50.9 & 51.1 & 53.6 & 58.8 \\
\hline HB75 & 58.9 & 60.9 & 46.0 & - & 68.5 & 69.4 & 70.6 & 63.0 \\
\hline WP50 & 69.8 & 55.0 & 50.9 & 68.5 & - & 99.4 & 81.2 & 70.9 \\
\hline WP75 & 70.3 & 55.0 & 51.1 & 69.4 & 99.4 & - & 83.1 & 71.8 \\
\hline WB50 & 76.2 & 52.3 & 53.6 & 70.6 & 81.2 & 83.1 & - & 83.3 \\
\hline WB75 & 87.6 & 48.2 & 58.9 & 63.0 & 70.9 & 71.8 & 83.3 & - \\
\hline Mean & 67.3 & 50.9 & 51.5 & 62.5 & 70.8 & 71.4 & 71.5 & 69.1 \\
\hline${ }^{*}$ W= pH 7.0 Buffer; H= HCl; P= Paddle; B= Basket; $50=50$ rpm;75=75 rpm. & & & & & \\
\hline
\end{tabular}

Table 3. The similarity factor, $f_{2}$, between different dissolution conditions for FC tablet

\begin{tabular}{|lcccccccc|}
\hline Dissolution Condition & HP50 & HP75 & HB50 & HB75 & WP50 & WP75 & WB50 & WB75 \\
\hline HP50 & - & 36.2 & 66.3 & 51.9 & 44.9 & 51.9 & 74.5 & 43.8 \\
\hline HP75 & 36.2 & - & 34.5 & 49.6 & 44.4 & 48.7 & 37.8 & 58.8 \\
\hline HB50 & 66.3 & 34.5 & - & 46.3 & 47.8 & 50.3 & 73.6 & 40.0 \\
\hline HB75 & 51.9 & 49.6 & 46.3 & - & 48.8 & 65.5 & 53.1 & 68.6 \\
\hline WP50 & 44.9 & 44.4 & 47.8 & 48.8 & - & 61.7 & 50.6 & 45.9 \\
\hline WP75 & 51.9 & 48.7 & 50.3 & 65.5 & 61.7 & - & 57.3 & 57.1 \\
\hline WB50 & 74.5 & 37.8 & 73.6 & 53.1 & 50.6 & 57.3 & - & 44.9 \\
\hline WB75 & 43.8 & 58.8 & 40.0 & 68.6 & 45.9 & 57.1 & 44.9 & - \\
\hline Mean & 52.8 & 44.3 & 51.3 & 54.8 & 49.2 & 56.1 & 56.0 & 51.3 \\
\hline${ }^{*}$ W= pH 7.0 Buffer; H= HCl; P= Paddle; B= Basket; 50= 50 rpm;75=75 rpm. & & & & & \\
\hline
\end{tabular}

mentioned spectrophotometric method. Cumulative percentages of the drug dissolved from the products were calculated and plotted vs. time.

\section{4 Applied method to compare dissolution profiles}

The description of the in vitro dissolution profiles by using model-independent methods includes the calculation of mean dissolution time (MDT) from the dissolution profile, mean residence time (MRT) from the residence profile, or area under the dissolution curve. In vitro dissolution profiles can statistically be compared through these parameters (14 and 15). In this study, as model-independent approaches, two fit factors that compare the dissolution profiles of a pair of drug products were applied to the dissolution data. These fit factors directly compare the difference between percent drug dissolved per unit time for a test and a reference product. The fit factors are denoted $\mathrm{f} 1$ (difference factor), and f2 (similarity factor) and are defined by Equations. (1) and (2) (16):

$$
\begin{aligned}
& f_{1}=\left\{\frac{\sum_{t=1}^{n}\left[R_{t}-T_{t}\right]}{\sum_{t=1}^{n} R_{t}}\right\} \times 100 \\
& f_{2}=50 \log \left\{\left(1 \div \frac{1}{n} \sum_{t=1}^{n}\left(R_{t}-T_{t}\right)^{2}\right)^{-0.5} \times 100\right\}
\end{aligned}
$$


Table 4. The similarity factor, $\mathrm{f}_{2}$, between different dissolution conditions for SC tablet

\begin{tabular}{|lcccccccc|}
\hline Dissolution Condition* & HP50 & HP75 & HB50 & HB75 & WP50 & WP75 & WB50 & WB75 \\
\hline HP50 & - & 70.3 & 67.5 & 76.6 & 45.3 & 60.8 & 71.6 & 48.9 \\
\hline HP75 & 70.3 & - & 73.2 & 61.2 & 42.8 & 53.1 & 66.5 & 49.1 \\
\hline HB50 & 67.5 & 73.2 & - & 57.3 & 39.2 & 49.2 & 57.6 & 43.4 \\
\hline HB75 & 76.6 & 61.2 & 57.3 & - & 50.3 & 73.4 & 76.5 & 52.4 \\
\hline WP50 & 45.3 & 42.8 & 39.2 & 50.3 & - & 58.1 & 51.1 & 61.4 \\
\hline WP75 & 60.8 & 53.1 & 49.2 & 73.4 & 58.1 & - & 67.7 & 56.3 \\
\hline WB50 & 71.6 & 66.5 & 57.6 & 76.5 & 51.1 & 67.7 & - & 57.7 \\
\hline WB75 & 48.9 & 49.1 & 43.4 & 52.4 & 61.4 & 56.3 & 57.7 & - \\
\hline Mean & 63.0 & 59.5 & 55.3 & 64.0 & 49.7 & 59.8 & 64.1 & 52.7 \\
\hline${ }^{*}$ W= pH 7.0 Buffer; H= HCl; P= Paddle; B= Basket; 50= 50 rpm;75=75 rpm. & & & & & \\
\hline
\end{tabular}

where $\mathrm{n}$ is the number of dissolution sample times, and $R_{t}$ and $T_{t}$ are the individual or mean percent dissolved at each time point, $t$, for the reference and test dissolution profiles, respectively.

\section{Results and Discussion}

The dissolution results as the means of percents dissolved versus time for commercially available tablets and capsules of clomipramine $\mathrm{HCl}$ are given in Figures 1 through 3.

Each data point represents a mean of nine measurements for each product. All drug products had percent of amount dissolved not less than $80 \%$ of the labeled amount of clomipramine $\mathrm{HCl}$ within $30 \mathrm{~min}$. The dissolution method and specification are set by considering the solubility, permeability, dissolution, and pharmacokinetics of the drug substance. Three categories of dissolution test specification for immediate release products are described in the guidance provided by the Center for Drug Evaluation and Research at the Food and Drug Administration (7): (a) single point specifications, (b) two-point specifications, and (c) dissolution profile comparison. The dissolution profile comparison seems to be more precise than the point estimate approach to characterize the drug product (18-20). The methods for the comparison of in vitro dissolution profiles can be classified into three groups: (a) the methods based on analysis of variance (ANOVA) (14 and 18), (b) modeldependent methods (2,14, and 18), and (c) model-independent methods $(2,13,14,15$, and 19). A model-independent method uses the dissolution data in their native form and was used in this study. The $\mathrm{f} 1$ (difference factor) is proportional to the average difference between the two profiles, whereas $\mathrm{f} 2$ (similarity factor) is inversely proportional to the average squared difference between the two profiles, with emphasis on the larger difference among all the time points. The use of these factors was also recommended for
Table 5. The similarity factor, $f 2$, between capsule, sugar coated (SC) tablets and film coated (FC) tablets

\begin{tabular}{|lccc|}
\hline $\begin{array}{l}\text { Dissolution } \\
\text { Condition* }\end{array}$ & $\begin{array}{l}\text { FC Tablet (T) } \\
\text { Compared to } \\
\text { Capsule (R1) }\end{array}$ & $\begin{array}{c}\text { FC Tablet (T) } \\
\text { CC Tablet (R2) }\end{array}$ & $\begin{array}{c}\text { Capsule } \\
\text { Compared to } \\
\text { SC Tablet }\end{array}$ \\
\hline HP50 & 31.8 & 26.6 & 15.3 \\
\hline HP75 & 34.8 & 21.9 & 13.9 \\
\hline HB50 & 34.1 & 22.2 & 13.8 \\
\hline HB75 & 33.7 & 26.0 & 15.6 \\
\hline WP50 & 33.6 & 29.2 & 23.8 \\
\hline WP75 & 35.0 & 20.9 & 16.3 \\
\hline WB50 & 29.6 & 16.6 & 18.4 \\
\hline WB75 & 44.4 & 25.3 & 19.6 \\
\hline${ }^{*}$ W= pH 7.0 Buffer; H= HCl; P= Paddle; B= Basket; 50= 50 rpm;75=75 rpm. \\
\hline
\end{tabular}

dissolution profile comparison in the FDA's guides for industry (7) and in this study $f 2$ was calculated and used. According to these guides, $\mathrm{f} 2$ values greater than 50 (50-100) would indicate sameness or equivalence of the two curves. F2 factors for each clomipramine dosage form (FC Tablets, $\mathrm{T}$; Capsule, $\mathrm{R}_{1}$; or SC Tablets $\mathrm{R}_{2}$ ) at each dissolution condition versus other dissolution conditions were calculated from the means of percent dissolved at each time point by using Equation 2 and listed in tables 2 through 4 .

The values of factor $\mathrm{f} 2$ were calculated for the dissolution up to 30 minutes (the time at which $80 \%$ of drug substance is dissolved from any tested drug product). As can be seen in tables 2 through 4 , mean of $\mathrm{f} 2$ factor for each condition compared to other conditions were calculated and showed 
Table 6. The similarity factor, $f_{2}$, between 10,25 , and $50 \mathrm{mg}$ clomipramine capsules or tablets

\begin{tabular}{|l|c|c|c|c|c|c|}
\hline & \multicolumn{5}{|c|}{ Capsule } & \multicolumn{3}{c|}{ Tablet } \\
\hline $\begin{array}{l}\text { Dissolution } \\
\text { Condition }\end{array}$ & $\begin{array}{c}10 \mathrm{mg} \text { vs } \\
25 \mathrm{mg}\end{array}$ & $\begin{array}{c}10 \mathrm{mg} \text { vs } \\
50 \mathrm{mg}\end{array}$ & $\begin{array}{c}25 \mathrm{mg} \text { vs } \\
50 \mathrm{mg}\end{array}$ & $\begin{array}{c}10 \mathrm{mg} \text { vs } \\
25 \mathrm{mg}\end{array}$ & $\begin{array}{c}10 \mathrm{mg} \text { vs } \\
50 \mathrm{mg}\end{array}$ & $\begin{array}{c}25 \mathrm{mg} \text { vs } \\
50 \mathrm{mg}\end{array}$ \\
\hline HP50 & 83.5 & 65.7 & 74.6 & 19.0 & 10.7 & 34.0 \\
\hline HP75 & 49.5 & 45.1 & 79.5 & 29.9 & 41.3 & 26.6 \\
\hline HB50 & 42.8 & 47.3 & 67.3 & 29.7 & 14.8 & 29.9 \\
\hline HB75 & 52.8 & 44.2 & 44.3 & 13.8 & 9.0 & 43.7 \\
\hline WP50 & 40.3 & 64.4 & 39.2 & 54.7 & 28.8 & 34.8 \\
\hline WP75 & 46.1 & 41.2 & 58.3 & 45.9 & 17.8 & 22.1 \\
\hline WB50 & 63.8 & 60.4 & 64.7 & 6.8 & 14.3 & 29.9 \\
\hline WB75 & 52.8 & 34.5 & 44.6 & 46.1 & 21.5 & 29.5 \\
\hline${ }^{*}$ W= pH 7.0 Buffer; H= HCl; P= Paddle; B= Basket; $50=50$ rpm; $75=75$ rpm. & & & \\
\hline
\end{tabular}

at the bottom of each column in tables. As an example, the mean value for column 1 in table 2 indicates the average of $\mathrm{f} 2$ values of HP50 dissolution condition compared to seven other conditions that were employed in this study (of course except itself). Lowest $\mathrm{f} 2$ values in tables that indicate the largest difference between dissolution conditions were highlighted. Results showed that smallest $\mathrm{f} 2$ values for capsules were achieved in HP75 condition despite the mean $\mathrm{f} 2$ is greater than 50 but in this column, there are three $\mathrm{f} 2$ values lower than 50 . Therefore it can be concluded that this condition is a more discriminating condition for capsules. Discriminating conditions for FC tablets and SC tablets are also HP75 and WP50, respectively. F2 factors for T vs R1, T vs R2, and R1 vs R2 were calculated and were shown in table 5 . F2 values were lower than 50 , indicating that all dissolution profiles of dosage forms were different from each other. Results of dissolution data show that all dissolution conditions have discriminating properties for studying of clomipramine products. The release rates from capsules are faster than film coated tablets at each dissolution condition and dissolution from film coated tablets are faster than sugar coated tablet in every dissolution condition. The difference in dissolution profiles of different dosage forms of clomipramine $\mathrm{HCl}$, without considering the dissolution conditions, indicate that for a freely soluble drug such as clomipramine $\mathrm{HCl}$, its intrinsic dissolution rate is very fast, and the release rate of drug from its dosage form could be affected primarily by a factor such as the formulation. Comparison of dissolution profiles of different strengths of the same dosage form (capsule or tablet) by $\mathrm{f} 2$ factor (table 6) show that in some dissolution conditions such as HP50 and WB50, all strengths of capsules have similar dissolution profiles. However, in the other conditions, two of the three strengths for capsules, and in every condition, all strengths of the tablets, are different.
These results show that in conditions such as WB50, in which all strengths of capsules are similar, the biggest difference is between different strengths of tablets. Therefore it seems that if we want to use dissolution conditions which have the most discriminating properties for capsules and film coated tablets, we must use $\mathrm{HCl} 0.1 \mathrm{~N}$ as a medium, USP Apparatus 2 (paddle) as dissolution apparatus and stirring speed of $75 \mathrm{rpm}$ and for sugar coated tablets we must use buffer pH 7.0 as a medium, USP Apparatus 2 (paddle) as dissolution apparatus and stirring speed of $50 \mathrm{rpm}$ in which the mean of $\mathrm{f} 2$ factors for all strengths of dosage forms are the lowest, indicating a greater difference for dissolution.

\section{Conclusion}

Dissolution testing is a very important in vitro test to evaluate drug products. Clomipramine $\mathrm{HCl}$, used in some depressive conditions such as obsessive compulsive disorders, has no reliable dissolution conditions in its monograph in BP or USP. In this study, we concluded that, if we want to use the most discriminating conditions for dissolution testing of clomipramine capsules or film coated tablets, a $\mathrm{HCl}$ media, paddles, and stirring speed of $75 \mathrm{rpm}$ should be used, and for sugar coated tablets, buffer pH 7.0, paddles, and stirring speed of $50 \mathrm{rpm}$ appear to be the best conditions.

\section{References}

1. C.K. Carrico, “Workshop report-AAPS:USP workshop on dissolution calibration and testing", Pharm. Res. 13(1996) 6-9.

2. V.P. Shah, L.J. Lesko, J. Fan, N. Fleischer, J. Handerson, H. Malinowski, M. Makary, L. Ouderkirk, S. Roy, P. Sathe, G.J.P.Singh, L. Tillman, Y. Tsong, R.L. Williams, "FDA guidance for industry: dissolution testing of immediate release solid oral dosage forms", Dissolution Technol. 4(1997) 15-22. 
3. B. Hoener, L.Z. Benet, in: G.S. Banker, C.T. Rhodes (Eds.), Modern Pharmaceutics, Marcel Dekker, New York, (1990), pp. 143.

4. E. D. Jorgensen, D. Bhagwat, Pharm. Sci. Technol. Today 1 (1998) 128-135.

5. USP 25, the United States Pharmacopeial Convention, Rockville, MD, USA, (2002), pp. 2011-2012 and 2258-2259.

6. The European Pharmacopoeia, fourth ed., Council of Europe, Strasbourg, (2002), pp. 194-197.

7. FDA, Guidance for Industry: Dissolution testing of Immediate Release Solid Oral Dosage Forms, (1997).

8. International Pharmaceutical Federation (FIP) guidelines for dissolution testing of solid oral products, Drug Inf. J. 30 (1996) 1071-1084.

9. S. A. Qureshi, I. J. McGilveray, "Typical variability in drug dissolution testing: study with USP and FDA calibrator tablets and a marketed drug (glibenclamide) product", Eur. J. Pharm. Sci. 7 (1999) 249-258.

10. A. Frick, H. Moller, E. Wirbitzki, “Biopharmaceutical characterization of oral immediate release drug products. In vitro/in vivo comparison of phenoxymethylpenicillin potassium, glimepiride and levofloxacin”, Eur. J. Pharm. Biopharm. 46 (1998) 305-311.

11. E. Galia, E. Nicolaides, D. Horter, R. Lobenberg, C. Reppas, J. B. Dressman, “Evaluation of various dissolution media for predicting in vivo performance of class 1 and II drugs", Pharm. Res. 15 (1998) 698-705.
12. V. J. Stella, S. Martodihardjo, K.Terada, M. R. Venkatramana, "Some relationships between the physical properties of various 3-acyloxymethyl prodrugs of phenytoin to structure: potential in vivo performance implication", J. Pharm. Sci. 87 (1998) 1235-1241.

13. F. Podczeck, "Comparison of in vitro dissolution profiles by calculating mean dissolution time (MDT) or mean residence time (MRT)", Int. J. Pharm. 97(1993) 93-100.

14. J. E. Polli, G. S. Rekhi, L. L. Augsburger, V. P. Shah, "Methods to compare dissolution profiles and a rationale for wide dissolution specifications for metoprolol tartrate tablets", J. Pharm. Sci. 86(1997) 690-700.

15. J.W. Moore, H. H. Flanner, "Mathematical comparison of dissolution profiles", Pharm. Technol. June (1996) 64-74.

16. V. P. Shah, Y. Tsong, P. Sathe, R. L. Williams, "Dissolution profile comparison using similarity factor, $f 2$ ", Dissolution Technol. 6(1999) 15.

18. P. M. Sathe, Y. Tsong, V. P. Shah, "In vitro dissolution profile comparison: statistics and analysis, model dependent approach", Pharm. Res. 13(1996) 1799-1803.

19. V. P. Shah, Y. Tsong, P. Sathe, J.P. Liu, "In vitro dissolution profile comparison statistics and analysis of the similarity factor, f2". Pharm. Res. 15(1998) 889-896.

20. J. W. Mauger, D. Chilko, S. Howard, "On the analysis of the dissolution data", Drug Dev. Ind. Pharm. 12(1986) 969-992. 